\title{
O USO DO CHAT DE VOZ NA APRENDIZAGEM ONLINE: UMA EXPERIÊNCIA NA MARINHA DO
} BRASIL

The use of voice chat in online learning: one experience in the brazilian navy

Lourival José Passos Moreira* Lúcia Regina Goulart Vilarinho**

\section{Resumo}

O presente trabalho constitui parte de uma pesquisa realizada na implantação de um curso de Inglês online na Marinha do Brasil, a qual buscou identificar como professores-tutores e alunos, civis e militares da ativa, vinculados a esta corporação militar, perceberam o curso, considerando seus elementos constitutivos, a saber: planejamento, conteúdo, material didático, tutoria e processo de avaliação. Dada à abrangência da pesquisa, os resultados ora apresentados referem-se apenas ao uso do chat de voz em aulas de conversação online. Na visão desses sujeitos são apontadas as dificuldades e vantagens deste tipo de prática online.

Palavras-chave: Educação a distância. Chat de voz. Prática online.

\section{Abstract}

This article presents part of a research conducted during the implementation of an English online course in brazilian Navy. The main objective was to establish

* Professor do CEFET/RJ e da Escola Naval; mestre em Educação pela Universidade Estácio de Sá. Email: lourivalmoreira@gmail.com

** Professora da Universidade Estácio de Sá (UNESA-RJ); mestrado e doutorado em Educação pela Universidade Federal do Rio de Janeiro. Email: lgvilarinho@netbotanic.com.br 
the perceptions of tutors and students about this online course considering its constitutive elements: planning, contents, didactic material, tutoring and evaluation process. Given the scope of the research, the results showed here refers only to the voice chat activities, pointing out the difficulties and advantages faced by those subjects.

Keywords: Distance learning. Voice chat. Online practices.

\section{INTRODUÇÃO}

Em julho de 2005, a Marinha do Brasil (MB) deu início a um Curso de Inglês online, veiculado pela Intra-Internet, organizado em parceria com a Cultura Inglesa, atendendo cerca de 500 alunos, civis e militares, pertencentes a diferentes níveis hierárquicos no âmbito dessa instituição e possuidores de distintas escolaridades.

A proficiência em língua inglesa é requisito importante em atividades de comunicação que envolvam pessoal da $\mathrm{MB}$ com marinhas estrangeiras amigas, seja em operações de guerra ou treinamentos conjuntos, comunicações com navios de bandeira estrangeira em nossas águas, operações de resgate, programas de intercâmbio e cursos no exterior, reuniões de Estado Maior ou outras missões fora do País.

Tendo este requisito como "pano de fundo", o projeto pedagógico do curso em tela baseou-se na abordagem de competências, entendidas como "capacidade de mobilizar diversos recursos cognitivos para enfrentar um tipo de situação” (PERRENOUD, 2000). Partindo de situações simuladas e contextualizadas de comunicação, o curso se propõe a desenvolver os níveis de habilidades e competências definidos pela The Association of Language Testers in Europe (ALTE, 2006). Esta associação, criada em 1989, ocasião em que era constituída apenas por duas universidades, Cambridge e Salamanca, conta, atualmente, com 28 membros, abrangendo 24 diferentes línguas de uso na Europa. Planejada de forma modular, a proposta visa o desenvolvimento de habilidades de conversação, leitura e redação nos níveis definidos pela ALTE. 
Entre as características inéditas deste curso a distância destaca-se 0 uso do chat de voz (voice chat). Acreditando que a diferença de patentes poderia ser um elemento de interferência negativa no desenvolvimento das atividades online, especialmente naquelas dirigidas à conversação, a coordenação do curso optou pela participação dos alunos, em todas as etapas, descaracterizados de suas patentes militares. Esta estratégia visou, sobretudo, reduzir as inibições naturais da conversação, já observadas em aulas presenciais no contexto militar.

A utilização da tecnologia do chat de voz representa uma inovação educacional que exige uma reflexão crítica sobre suas implicações. As ferramentas de comunicação virtual em chat têm sido predominantemente escritas; assim, a inclusão da comunicação audiovisual pode representar uma significativa revolução (MORAN apud SILVA, 2003), trazendo novos desafios. Esta inovação exige uma avaliação acurada de suas limitações e vantagens. Alguns desafios que se apresentam ao uso do chat de voz já são bem conhecidos, porque também se expressam em aulas presenciais. Outros, no entanto, como a forma de organizar a seqüência das discussões, o conteúdo das intervenções de alunos e tutores, o controle de dispersões desnecessárias, o incentivo à participação dos alunos, a negociação com os alunos que tendem a monopolizar a fala, trazem novas questões para a prática pedagógica no contexto da Educação a Distância (EAD).

Este artigo constitui parte de uma pesquisa cujo objetivo mais amplo foi estabelecer como os alunos, militares e civis da Marinha, perceberam o curso de Inglês online, considerando seus elementos básicos, a saber: planejamento, conteúdo, material didático, tutoria e processos de avaliação. Tratou-se, portanto, de uma investigação inserida no âmbito da Didática, tendo como foco um processo de auto-formação profissional em serviço, concretizado pelo ensino-aprendizagem a distância e mediatizado por tecnologias de informação e comunicações. A parte aqui apresentada referese à identificação de vantagens e limitações decorrentes do uso do chat de voz com descaracterização de patentes militares (postos/graduações).

Os dados relativos a esta parte da pesquisa foram obtidos por meio de observação de campo, conduzida no ambiente virtual de aprendizagem (AVA) do curso e na própria Escola Naval, onde os professores-tutores 
foram entrevistados. Os alunos participaram da pesquisa respondendo a questionários semi-estruturados, encaminhados via web. Para analisar as informações coletadas, optou-se por procedimentos metodológicos que incluíram tanto a quantificação de aspectos recorrentes encontrados nas falas dos participantes, como o estabelecimento de inferências a partir dessas mesmas falas, orais e escritas. Cabe salientar que o estudo qualitativo dos resultados baseou-se em orientações de Bardin (2000), específicas para a análise de conteúdos de discursos.

O foco de nossas observações foram as aulas de conversação a distância que utilizaram recursos de voice chat disponíveis no AVA do curso, desenvolvido e mantido pela Cultura Inglesa.

\section{O CONTEXTO DO CHAT DE VOZ}

O AVA do curso possui ferramentas que permitem a interatividade entre alunos e tutores com apoio de cinco interfaces principais: (a) tira dúvidas (Ask a Question): onde alunos podem fazer perguntas para equipe de tutores; (b) diálogo professor-aluno (One to One): que se realiza por um serviço de chat (sala de bate-papo), com diálogos escritos, interativos e em tempo real; (c) redação: que estimula o aluno a enviar redações que são devolvidas corrigidas e comentadas pelo professor; (d) bate-papo de voz (Voice Chat): onde acontecem as aulas de conversação com o moderador; e (e) apoio contínuo - que se dá por meio de contato com professor via e-mail e telefone.

A prática oral é desenvolvida em uma aula de conversação online, no ambiente de voice chat. A interface do aluno é mostrada na figura 1 . À direita da tela aparece uma página de web, que é usada como apoio à conversação. No canto inferior esquerdo são apresentados o rol de participantes e o indicativo da qualidade da conexão. Também é ali que se situam os controles de volume e de microfone. A interface dispõe de um chat de texto no lado superior esquerdo, no qual os estudantes podem interagir com a professora, paralelamente à conversação em áudio. $\mathrm{O}$ chat de texto nesta interface tem caráter complementar: possibilita, por exemplo, o envio pela professora de alguma palavra que ajude o estudante a construir uma sentença durante a conversação. 


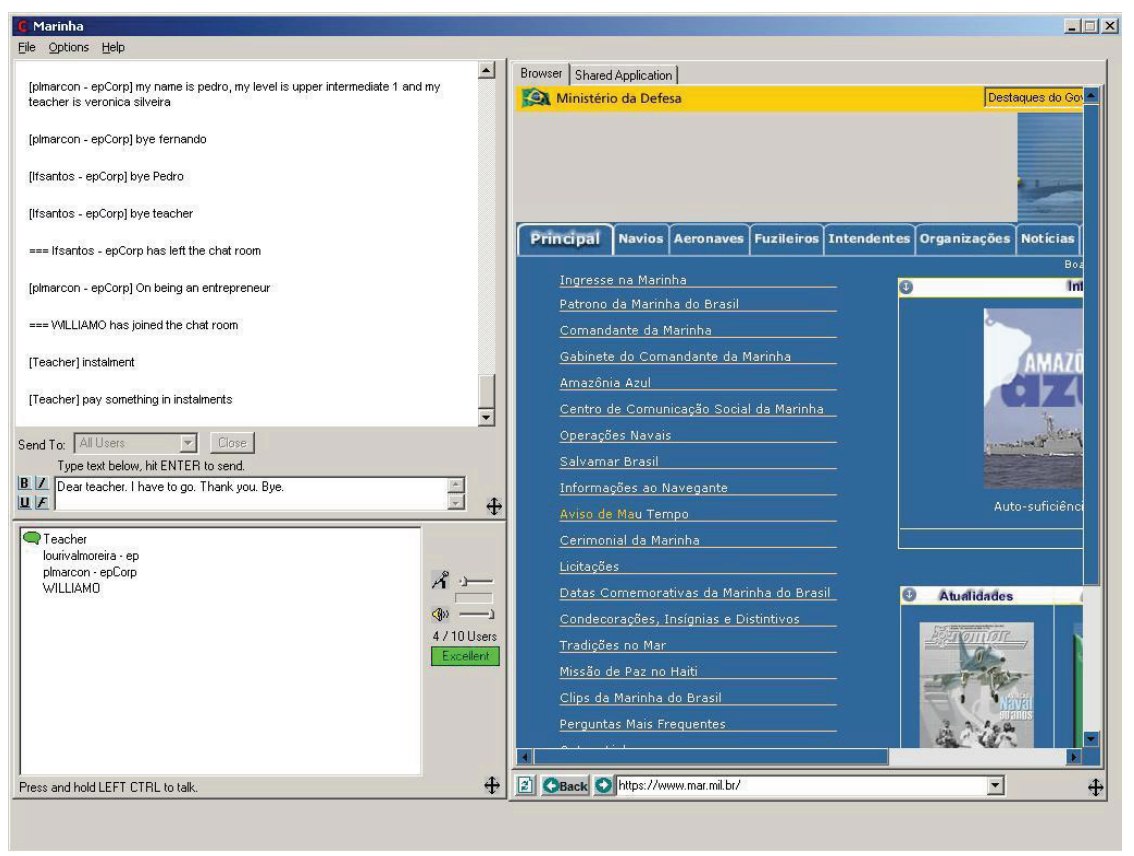

Figura 1 - Atividade de Conversação (Voice Chat)

Apesar dos alunos deste curso estarem dispersos geograficamente, eles podem se reunir pelos mesmos processos telemáticos e plataformas comunicacionais, que acoplam ferramentas sóciotecnológicas. Podem, também, vivenciar trocas a distância em tempo real por intermédio de interações midiáticas, capazes de promover experiências interativas nas quais diferentes ecologias cognitivas se expressam (MEDEIROS apud SILVA, 2003). Essas interações interpessoais adquirem uma nova dimensão no âmbito de atividades em que os alunos encontram-se descaracterizados de suas patentes. Neste sentido, observou-se que os processos de engajamento nas atividades foram mais orientados pelo grau de motivação individual do que pela hierarquia posta pela patente ou pelo nível de escolaridade. 


\section{INOVAÇÃO TECNOLÓGICA REQUER INOVAÇÃO PEDAGÓGICA}

O aumento progressivo da velocidade da circulação das informações na capacidade de processamento e armazenamento dos dados, bem como a microminiaturização dos circuitos eletrônicos em chips, que favorece amplas coberturas geográficas com apoio dos sistemas de telecomunicações, confere um caráter revolucionário às tecnologias informacionais (BOHADANA, 2005). São os tecnobergs, ou seja, “complexo capacitador tele-info-computrônico satelital" (DREIFUSS, 1996, p.25), redimensionando as instituições responsáveis pela formação do sujeito, como a educação, a religião e a família.

Observa-se, na contemporaneidade, o barateamento, a difusão e, conseqüentemente, uma democratização gradativa de suportes de tecnologias de ponta usados em educação. A EAD digital, que era predominantemente silenciosa, hipertextual e muito estática do ponto de vista gráfico, passa a explorar mais recursos de hipermídia, com imagens e hipertextos mais dinâmicos, usando intensivamente, de forma síncrona ou assíncrona, recursos de áudio e vídeo. Aumentase, também, a acessibilidade dos alunos com o uso de sistemas móveis de comunicação, redes sem fio, equipamentos portáteis e celulares inteligentes, fazendo emergir novos conceitos como a EAD móvel (m-learning). Com estes avanços tecnológicos evoluem os ambientes virtuais de aprendizagem, os sistemas de autenticação, as grids de dados, os sistemas de realidade virtual e a telepresença. As tendências tecnológicas começam a influenciar os paradigmas da EAD digital, uma vez que o uso de recursos mais sofisticados, como videoconferência e chat de voz, tornam-se cada vez mais comuns.

Toda essa evolução tecnológica obriga e resulta em uma busca de inovações pedagógicas. Os novos recursos tecnológicos tornam possíveis práticas educativas mais atrativas e inovadoras e exigem outros enfoques metodológicos (MACHADO, 2005). O professor assume novos papéis e a dimensão tecnológica dos saberes docentes, além das perspectivas pedagógica e didática, ganha maior relevância (BELLONI, 2002). 


\section{RESULTADOS DO ESTUDO}

\section{As dificuldades reveladas nas observações de campo}

Diferentes aulas de conversação foram acompanhadas nesta pesquisa. $\mathrm{O}$ investigador entrava na sala, identificava-se junto à professora e pedia autorização para acompanhar a atividade. A presença do pesquisador foi passiva: não participou das interações, nas ocasiões em que havia aluno no ambiente. Com o objetivo de facilitar posterior análise, os diálogos das aulas foram gravados. Esta gravação era feita diretamente no computador com o programa Audacity, de licença gratuita e que pode ser obtido em site de Internet (http://audacity.sourceforge.net/download/). Este programa, além de capturar o áudio, apresenta um gráfico de amplitudes e tempo, o que facilitou a posterior análise dos dados.

Após a observação de algumas seções de voice chat, alguns problemas ficaram evidentes: uns de natureza técnica, outros de natureza processual. Entre os problemas de natureza técnica encontrou-se: (a) dificuldade de acesso ao ambiente de conversação; (b) a qualidade instável da conexão, com possíveis quedas; (c) a perda de conexão do professor, com necessidade de mudar de apelido (nickname) para poder retornar; e (d) problemas na reprodução do áudio.

Em relação aos problemas na reprodução do áudio, quatro tipos influenciaram o ritmo da fala: (a) pausas longas entre falas; (b) diferenças nos níveis de volume; (c) quebra de palavras ou sentenças; e (d) repetições.

$\mathrm{O}$ primeiro desses problemas - pausas com longos períodos de silêncio, que afetam o ritmo da aula - provoca a sensação de 'demora' para os participantes. É um elemento difícil de ser controlado ou evitado, pois depende de fatores como o tempo necessário para um aluno pensar e responder, quando um professor a ele se dirige. Também depende da velocidade da conexão, que pode ser lenta para alguns alunos, e que deve ser rápida para o professor, considerando que é o moderador do processo. A figura 2 ilustra uma ocorrência dessa natureza com o recorte de uma aula de conversação no Online Course.

Durante as seções de conversação também foram observadas diferenças acentuadas no nível de volume de áudio entre as falas dos 


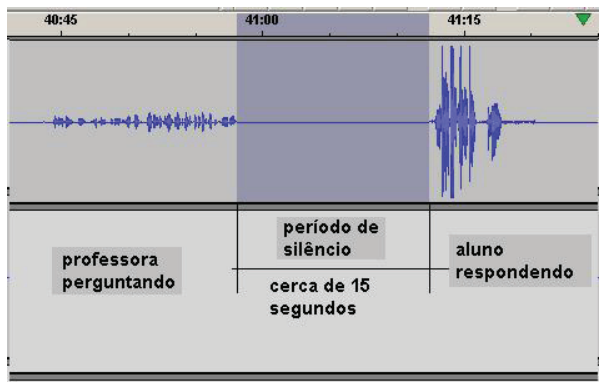

Figura 2 - Pausa Longa.

participantes. Assim, quando uma fala muito baixa se encontra em execução, ela produz uma dificuldade, obrigando os outros participantes a aumentarem o volume de reprodução, para que fique compreensível. E quando esta fala baixa é seguida por outra, com alto volume, verifica-se uma espécie de 'transição', que provoca uma sensação de desconforto auditivo ('volume alto'), levando os ouvintes a abaixarem o volume de áudio no computador. Este problema seria minimizado se a interface dispusesse de um recurso de equalização de nível. A figura 3 apresenta uma ocorrência deste tipo, durante uma aula de conversação.

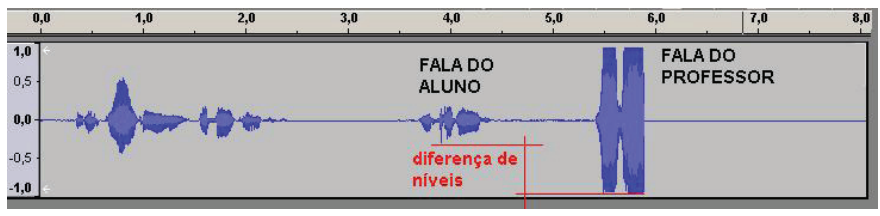

Figura 3 - Diferença de Níveis de Volume.

Não foram percebidos ruídos superpostos às falas durante os períodos de observação.

Outro problema revelado foi a quebra de sentenças ou palavras. Assim, quando o fluxo de áudio era interrompido no meio de uma frase ou palavra, constatava-se um intervalo de silêncio, e a reprodução era, então, retomada. A sensação produzida no ouvinte era de 'quebra'. Um 
registro típico deste problema é mostrado na figura 4 . Nela se percebe que a mensagem foi gerada continuamente, mas a reprodução foi interrompida no meio da palavra 'você', ficando assim o fluxo da fala: [...] vou contar sua participação, até porque fiz algumas perguntas para vo [...]; interrupção e pausa por cerca de 9 segundos e continua: [...] ce, mas vou dar uma dica: da próxima vez[...]

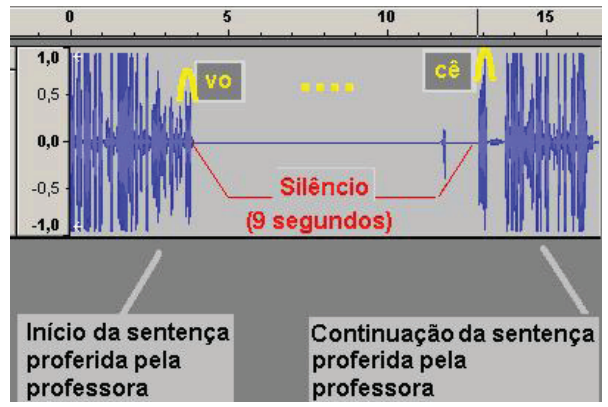

Figura 4 - Quebra de Palavra.

Algumas vezes as quebras foram acompanhadas de repetição, onde a reprodução do fluxo de áudio era interrompida; ocorria, assim, uma pausa de alguns segundos e o áudio era retomado repetindo o que já havia sido dito anteriormente. A figura 5 ilustra uma amostra de áudio com ocorrência de interrupção seguida de repetição. A sensação produzida no ouvinte é de 'gagueira' do locutor.

Embora esses problemas técnicos tenham ocorrido com pouca freqüência, não comprometendo o ritmo da aula, não se pode deixar de admitir que interferem no ritmo da conversação.

Outros problemas identificados nas sessões de voice chat foram: (a) dificuldades de alguns alunos em usar os controles da interface, como consequiência da falta de familiaridade como uso de computador; (b) aluno que chegava atrasado na seção agendada para seu nível, ficando tempo insuficiente para uma participação mais completa; (c) aluno que entrava adiantado em seção reservada a outro nível, ocupando lugar na sala virtual; e (d) aluno que apresentava uma desculpa técnica para não participar dos diálogos, embora presente na sala. 


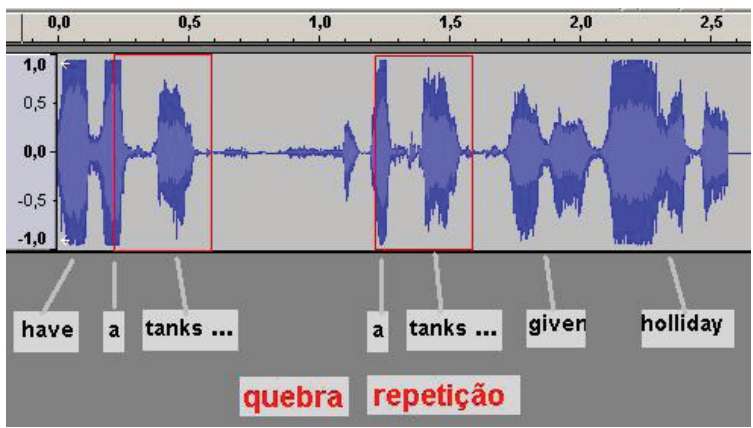

Figura 5 - Quebra de Sentença Seguida de Repetição.

Além de acompanhar as atividades online, o pesquisador entrevistou alguns dos docentes do curso, na Escola Naval, ocasião em que foram obtidos dados e comentários relevantes para uma melhor compreensão das dificuldades no uso do chat de voz. Os problemas a seguir apresentados foram os mais recorrentes nas falas dos docentes e mostram algumas percepções desses sujeitos em relação a este recurso.

Alguns professores expressaram preocupação em relação ao voice chat antes do início do curso, mas com a prática as resistências foram sendo desconstruídas. Um exemplo de 'quebra' de resistência está no comentário de um desses docentes, por ocasião da entrevista. Disse ele: [...] é estranho você falar com uma pessoa que você não está vendo $[. .$.$] mas quando você entra é uma conversa normal.$

Em relação à descaracterização de patentes militares (postos e graduações) no âmbito do voice chat, cabe salientar que os docentes a consideraram como uma inovação relevante. Eles entendem que quando se trata da aprendizagem de alunos em torno de objetivos comuns, no caso a aprendizagem da língua inglesa, a hierarquia determinadas pelas patentes não pode se constituir em fator de inibição, até porque, em diferentes situações, verificou-se que alunos com patente mais baixa apresentavam maior conhecimento da língua inglesa que outros, com patentes mais altas. Assim, os docentes se posicionaram favoravelmente à estratégia adotada. 


\section{A visão dos alunos: dificuldades e acertos no uso do voice chat}

As respostas oferecidas pelos alunos no questionário semi-estruturado, enviado via correio eletrônico, permitiram a identificação de vantagens e limitações em relação ao uso do chat de voz e à descaracterização de patentes. O retorno dos questionários ficou abaixo do esperado; apenas 13 alunos responderam ao instrumento, o que representou 4\% do número (325) de questionários enviados. Considerando, no entanto, que em uma abordagem qualitativa mais que a quantidade de respondentes importa a qualidade dos falantes (GONZÁLEZ REY, 2002) admitimos que se tornava necessário valorizar as respostas daqueles que tinham se interessado em responder ao questionário, pois isto denotava um compromisso com a melhoria do curso. Por outro lado, este baixo percentual de respostas norteou a decisão de ouvir também os professores, para que os resultados obtidos pudessem ser mais confiáveis e consistentes. O questionário continha três indagações direcionadas ao voice chat.

Tomando por base sua experiência nas atividades do chat de voz, reflita e responda.
1) O chat de voz contribuiu na sua aprendizagem?
(a) ( ) $\operatorname{Sim}(b)$ ( )Não

2) Quais as desvantagens e dificuldades encontradas nas atividades de chat de voz?

3) Que pontos positivos você apontaria no uso de chat de voz?

4) Como você vê a descaracterização de patentes nas atividades do chat de voz?

Quadro 1 - Questões enviadas aos alunos por e-mail sobre o uso do voice chat.

A maioria dos 13 respondentes (85\%) considerou que o chat de voz contribuiu para a aprendizagem. Os demais ou não responderam ou afirmaram que ainda não tinham participado da aula de conversação.

No que tange às dificuldades, os alunos apontaram dois tipos, a saber: técnicas e didático-pedagógicas. As dificuldades técnicas foram: os problemas observados no áudio do professor ou dos alunos, e/ou baixa qualidade de conexão. Os problemas de cunho didático-pedagógico foram 
quatro: a necessidade de um chat livre entre os estudantes, a velocidade na pronúncia das palavras, a inadequação entre a duração da aula e o número de participantes. É natural que a velocidade na pronúncia das palavras cause dificuldades de entendimento; para minorar este problema há necessidade de um cuidado especial dos professores. Durante as aulas de conversação acompanhadas pelo pesquisador, foi observado um cuidado do professor-tutor em falar pausadamente e em auxiliar o entendimento das palavras pronunciadas, escrevendo a grafia e significado. A inadequação do tempo de duração da aula de conversação e o número de alunos participantes estão diretamente relacionados: observou-se que aulas com muitos participantes exigiram do professor um grande esforço para manter uma dinâmica que propiciasse, a todos, oportunidade de participar. Foi comum a participação de alguns alunos monopolizando a fala; outros, mais tímidos, ficavam calados. Tais extremos constituíam desafios para 0 professor, que tinha de moderar e estimular uma participação equânime.

Os resultados também mostraram duas dificuldades de infraestrutura no âmbito da Organização Militar (OM) na qual o aluno estava servindo: disponibilidade da tecnologia (insuficiente) e qualidade da rede de dados.

Uma aluna expressou três dificuldades pessoais: ansiedade, insegurança e timidez. A ansiedade durante a aula de conversação ocasionou dificuldades de entendimento e a insegurança com o idioma provocou timidez.

Outras dificuldades foram encontradas em relação ao planejamento das aulas: dosagem inadequada do tempo de duração da aula online para o número de participantes e necessidade de oferta de horários de conversação à noite e aos sábados. A demanda por horários alternativos indica que é difícil, para os alunos realizarem as atividades de conversação na própria $\mathrm{OM}$, por estas ocorrerem no horário de almoço.

Assim, as dificuldades mais recorrentes foram os horários da conversação e a conexão: cada uma delas indicada por $23 \%$ dos alunos.

O gráfico 1 mostra o percentual de recorrência de cada tipo dificuldade nas aulas de conversação. Nele, fica claro que predominaram as dificuldades de planejamento, seguidas das dificuldades técnicas. 


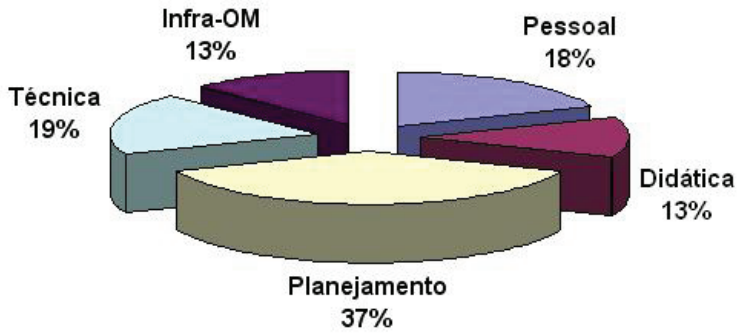

Gráfico 1 - Tipos de Dificuldades no Chat de Voz

As repostas dos alunos permitiram, então, que as dificuldades fossem agrupadas segundo a sua natureza, o que é apresentado no quadro que se segue.

\begin{tabular}{|c|c|c|}
\hline Categoria & Ocorrências & Natureza \\
\hline Conexão & 3 & Técnica \\
\hline Demanda de horários & 3 & Planejamento \\
\hline Duração da aula & 2 & Planejamento \\
\hline Ansiedade & 1 & Pessoal \\
\hline Chat entre alunos & 1 & Didática \\
\hline Disponibilidade de máquinas & 1 & Infra OM \\
\hline Insegurança & 1 & Pessoal \\
\hline Número de usuários por sessão & 1 & Planejamento \\
\hline Problemas de áudio & 1 & Técnica \\
\hline Timidez & 1 & Pessoal \\
\hline Velocidade de pronúncia & 1 & Didática \\
\hline
\end{tabular}

Quadro 2 - Dificuldades no Voice Chat

Uma outra questão do questionário buscava identificar os pontos positivos no uso de chat de voz, nas aulas de conversação online.

Os percentuais obtidos em cada categoria identificada no conjunto de respostas dos alunos são apresentados no quadro 3. Observa-se, então, que 
o acerto mais recorrente nas respostas oferecidas refere-se à desinibição da fala, proporcionada pela atividade, citada por 38\% dos alunos. Outro aspecto positivo bastante recorrente foi a possibilidade de praticar o idioma falado, apontada por $31 \%$ dos alunos. A interação entre alunos, propiciada pela aula de conversação, foi outra vantagem percebida por $23 \%$ dos alunos. A atuação docente, como apoio ao domínio da conversação, foi apontada por $23 \%$ dos alunos. Eles destacaram, ainda, a correção da pronúncia em tempo real, indicada por $15 \%$ dos sujeitos. A diversidade de assuntos, a familiarização com o idioma e a fixação de conteúdos foram indicadas por $8 \%$ dos alunos.

\begin{tabular}{|c|c|}
\hline Categorias & Percentuais de Alunos \\
\hline Desinibição & $38 \%$ \\
\hline Prática & $31 \%$ \\
\hline Dedicação docente & $23 \%$ \\
\hline Interatividade & $23 \%$ \\
\hline Correção da pronúncia & $15 \%$ \\
\hline Diversidade de assuntos & $8 \%$ \\
\hline Familiarização com o idioma & $8 \%$ \\
\hline Fixação de conteúdo & $8 \%$ \\
\hline
\end{tabular}

Quadro 3 - Vantagens no Uso do Voice Chat

Essas mesmas categorias podem ser visualizadas no gráfico que se segue.

A visão dos alunos quanto à descaracterização de patentes, foi investigada por meio de uma questão aberta. Dos 13 respondentes, sete praças e seis oficiais, sete apresentaram respostas favoráveis a essa estratégia (três oficiais e quatro praças, o que perfaz um percentual de $54 \%$ desses sujeitos). O percentual de aprovação entre os praças (57\%) foi maior que o encontrado entre os oficiais (50\%). Essa diferença não é significativa, mas era esperada face à questão da hierarquia militar. No entanto, cabe mencionar que os três oficiais favoráveis à descaracterização se expressaram a partir de pressupostos interessantes. O primeiro afirmou que em sala de aula a autoridade é o professor; o segundo disse que a proposta ajuda a 


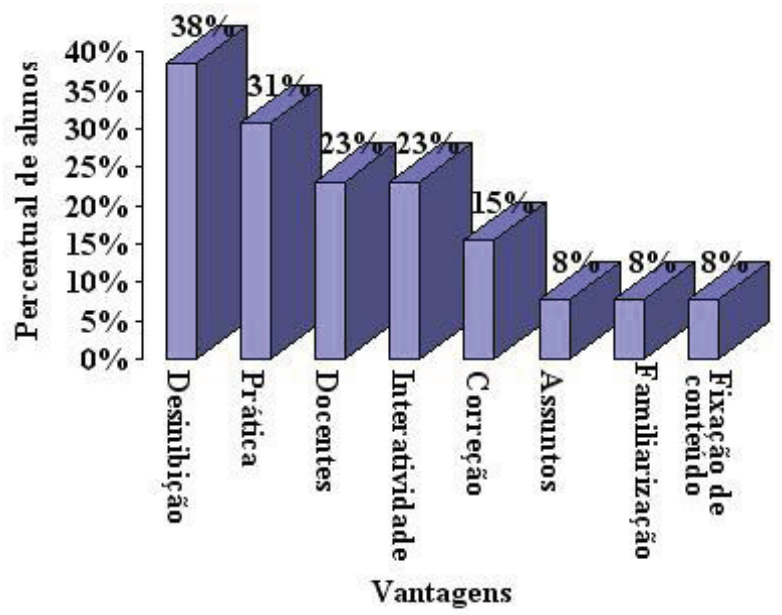

Gráfico 2 - Vantagens do Voice Chat: Distribuição Percentual de Alunos

desinibir os participantes (aqui infere-se que ele incluiu qualquer aluno, independente de sua patente); e o terceiro foi categórico, dizendo que não podia ser diferente, o que nos levou a interpretar sua fala como um comprometimento com a estratégia do curso. Já os quatro praças que se posicionaram favoravelmente apresentaram argumentos bem distintos. $\mathrm{O}$ primeiro considerou que não havia problemas, pois todos se tratavam com extremo cuidado e respeito; a proposta até facilitava a conversação. O segundo disse que não há necessidade de se saber com quem está conversando, o que importa é aplicar os conhecimentos transmitidos no curso (o que denota a objetividade do respondente). Já o terceiro foi lacônico, dizendo apenas que a experiência era excelente. E o quarto, apesar de admitir a intenção pedagógica da proposta, registrou que já tinham ocorrido algumas situações, fora do âmbito do curso em tela, em que a questão da hierarquia tinha atrapalhado as conversações. Sua resposta foi complementada por um comentário que julgamos pertinente transcrever, pois interessa não apenas aos gestores e professores do curso pesquisado, mas a todos aqueles que vão planejar e implementar um chat de voz, por colocar em destaque implicações da heterogeneidade grupal na aprendizagem. 
Por experiência própria, posso afirmar que quando se junta Oficiais e Praças da Marinha em atividades intelectuais, há um "desconforto mútuo" que é público e notório. Alguns tentam disfarçar, alguns negam veementemente, outros aprendem a lidar com isso, mas freqüentemente ocorrem constrangimentos.

Este comentário aponta a necessidade de uma discussão prévia (antecedendo a abertura do curso), envolvendo todos, alunos e professores, sobre as formas de colaboração e solidariedade que podem ser criadas quando pessoas diferentes se unem em torno de uma proposta pedagógica. Essa discussão tem que necessariamente centrar-se na perspectiva de que a aprendizagem se dá na relação social: o sujeito que se abre ao mundo e aos outros inaugura com seu gesto a relação dialógica em que se confirma como inquietação e curiosidade, como inconclusão em permanente movimento na História (FREIRE, 2003, p.136).

\section{CONCLUSÕES}

Os alunos consideraram que o chat de voz contribuiu para a aprendizagem. Das respostas pôde-se inferir que todos viram a descaracterização de patentes militares (postos e de graduações) nas aulas de conversação positivamente: a autoridade na sala de Chat é a professora; o tratamento entre os participantes foi permeado de cuidados e respeitoso, independente da presença de patentes mais elevadas. Esta sistemática torna mais fácil o desenrolar da conversação e evita situações de constrangimentos, que podem causar bloqueios e abandonos. Tais vantagens foram confirmadas nas observações de campo.

Os principais problemas e dificuldades apontados pelos alunos foram a necessidade de um chat livre entre os estudantes, a velocidade na pronúncia das palavras, a inadequação da duração da aula e o número de participantes. Verificou-se, também, que a falta de familiaridade com a interface dificultou ou inibiu a participação de alunos. Um outro problema apontado foi a indisponibilidade de máquinas (computadores e rede) para a realização da atividade na $\mathrm{OM}$.

A moderação do chat de voz revelou-se um desafio didático para os professores, mas estimulou a reflexão sobre esta nova prática docente online. 
As observações de campo revelaram problemas técnicos durante as aulas de conversação online, como dificuldade de acesso, baixa qualidade de conexão e falhas na reprodução do áudio.

Asvantagens apontadas pelos alunosforam: adesinibição, a possibilidade de praticar, a dedicação dos docentes, a interatividade, a correção imediata que é feita da pronúncia, a diversidade de assuntos explorados na aula, a familiarização com o idioma e a fixação de conteúdo.

Os alunos e professores participantes da pesquisa foram enfáticos em apontar a descaracterização como positiva, pois torna mais fácil o desenrolar da conversação e evita situações de constrangimentos, que podem causar bloqueios e abandonos.

\section{REFERÊNCIAS}

ASSOCIATION OF LANGUAGE TESTERS IN EUROPE ALTE. ALTE Social and Tourist typical abilities. Cambridge: The Association of Language Testers in Europe, 2006. Disponível em: <http://www.alte.org>. Acesso em: 20 de junho de 2006 .

BARDIN. Laurence. Análise de conteúdo. Lisboa: 70, 2000.

BELLONI, Maria Luiza. Educação a distância. Campinas: Autores Associados, 2002.

BOHADANA, Estrella. O terceiro milênio e a reconfiguração da humanidade: ética, educação e cultura. Disponível em: <http://www.redem.buap.mx/acrobat/ estrella1.pdf $>$. Acesso em: 10 de maio de 2005.

DREIFUSS, René A. A época das perplexidades. Petrópolis: Vozes, 1996.

FREIRE, P. Pedagogia da autonomia: saberes necessários à prática pedagógica. São Paulo: Paz e Terra, 2003.

GONZÁLEZ REY, Fernando Luis. Pesquisa qualitativa em Psicologia. São Paulo: Pioneira Thomson Learning, 2002.

MACHADO, Liliana Dias. O papel do tutor em ambientes online. Disponível em < http://www.abed.org.br/nordeste/downlaad/liliana.pdf $>$. Acesso em: 20/12/2005. 
o uso do chat de voz na...

PERRENOUD, Philippe. Dez novas competências para ensinar. Porto Alegre: Artmed, 2000.

SILVA, Marco (Org). Educação online. São Paulo: Loyola, 2003. 